\title{
INFLUENCE OF DIESEL SURROGATES ON THE BEHAVIOR OF SIMPLIFIED SPRAY MODELS
}

\author{
${ }^{1}$ Galle, Jonas ; ${ }^{1}$ Verhelst Sebastian \\ ${ }^{1}$ Department of Flow, Heat \& Combustion Mechanics, Ghent University, Belgium
}

KEYWORDS - 1D spray model, diesel, surrogates

\begin{abstract}
Numerous experimental investigations make use of diesel surrogates to make the computational time reasonable. In the few studies where measured (surrogate and real diesel) and computed (surrogate only) results have been compared, the selection methodology for the surrogate constituent compounds and the measures taken to validate the chemical kinetic models are not discussed, and the range of operating conditions used is often small. Additionally, most simplified models use tuning variables to fit model results to measurements.

This work makes the comparison between some frequently used diesel surrogates using a simple $1 \mathrm{D}$ vaporizing spray model, with the spray cone angle as the tuning parameter. Results show that liquid length and fuel fraction strongly depend on the physical properties of the used fuel for a fixed spray angle. These parameters are important for modeling auto-ignition and pollutant formation. The spray angle is varied till the spray length is the same for each surrogate. Results show important differences between other spray parameters such as local mixture fraction and axial velocity.
\end{abstract}

\section{ABBREVIATIONS \& SYMBOLS}

$\begin{array}{llll}\mathrm{c}_{\mathrm{p}} & \text { Heat capacity } & \mathrm{r} & \text { Radial position step } \\ \mathrm{D} & \text { Nozzle diameter } & \mathrm{R} & \text { Radius of the spray } \\ \mathrm{EGR} & \text { Exhaust Gas Recirculation } & \mathrm{R}_{\text {index }} & \text { Specific Gas constant } \\ \mathrm{f} & \text { Fuel mass fraction } & \mathrm{Sc} & \text { Schmidt number } \\ \mathrm{h} & \text { Enthalpy } & \mathrm{t} & \text { Time step } \\ \mathrm{I} & \text { Momentum } & \mathrm{T} & \text { Temperature } \\ \mathrm{k} & \text { Shape factor of a Gaussian profile } & \mathrm{u} & \text { Axial spray velocity } \\ \mathrm{Le} & \text { Lewis number } & \mathrm{UHC} & \text { Unburned Hydro-Carbons } \\ \mathrm{M} & \text { Molar mass } & \mathrm{x} & \text { Axial position step } \\ \dot{M} & \text { Mass flow rate } & \mathrm{Y} & \text { Mass fraction } \\ \mathrm{NO}_{\mathrm{x}} & \text { Nitrogen Oxides } & \theta & \text { Spray angle } \\ \mathrm{P} & \text { Pressure } & \rho & \text { Density } \\ \mathrm{Pr} & \text { Prandtl number } & \varphi & \text { Vapor fraction }\end{array}$

\section{INDICES}

$\begin{array}{llll}\text { a } & \text { ambient property } & \mathrm{i} & \text { position variable } \\ \mathrm{c} & \text { critical property } & \mathrm{j} & \text { time variable } \\ \mathrm{cl} & \text { property on spray axis } & \text { mix } & \text { mixture property } \\ \text { evap } & \text { total evaporation condition } & \text { sat } & \text { saturation property } \\ \mathrm{f} & \text { fuel property } & 0 & \text { initial condition }\end{array}$




\section{INTRODUCTION}

One of the main motives for combustion research is the increasingly stringent exhaust emission regulations to reduce the environmental impact. A further understanding of the combustion process and the possibility to model is needed in order to deal with the emission trade-offs. For direct injected diesel engines it is widely known that common-rail injection can lower soot and unburned hydrocarbon (UHC) emissions significantly as well as NOx, exhaust gas circulation (EGR) reduces nitrogen oxides (NOx) and slightly increases soot and UHC, supercharging decreases soot but slightly increases NOx. These statements depend on more parameters such as injection timing, inlet temperatures, engine load \& speed, combination of strategies, etc. The variety of parameters influencing the spray and combustion process makes the prediction of power output and emission formation very complex. For decades, researchers have been trying to understand and predict the in-cylinder processes by the use of experimental setups such as research engines and optical combustion chambers and modeling cases. One other issue is the fuel itself. The common fossil derived diesel fuel has a complex chemical composition and depends on the place of origin and production processes. This is the main reason to model with diesel surrogates. These diesel substitutes are chosen in such way that they approximate certain properties of fossil derived diesel fuel. Through this work, the term "diesel" will refer to fossil derived diesel. Usually only a few target properties are taken. The next paragraph gives an overview of commonly used surrogates and the motivation for choosing them. The second part describes the 1D spray model that will be used in this work to show (in the third section) that the choice of the surrogate fuel can significantly influence the results for a vaporizing spray.

\section{DIESEL SURROGATES}

Researchers have switched in the direction of using model fuels or surrogates in order to simplify the modeling efforts and to match application targets for conventional diesel combustion. Diesel has complex reaction kinetics and is a mixture of hydrocarbons of which composition depends on the place of origin, standards and production process. In general, the basic composition of diesel [1] consists of iso-parafins (25-50\%), cycloparafins (20-40\%) and aromatics (15-40\%).

Further, the wide range of hydrocarbon lengths makes it hard to predict the evaporation and combustion behavior; a boiling range $\left(190^{\circ} \mathrm{C}-300\right)$ is usually defined instead of a single boiling point for one component fuels.

Surrogates are selected based on one or a few chemical and physical properties which are comparable to diesel. Important parameters that are desired to meet those of diesel include chemical composition (determines strongly the combustion species and emissions), surface tension, viscosity, vapor/liquid equilibrium, distillation trajectory, molecular and thermal transport properties,... Moreover, most parameters vary with temperature and pressure, suggesting that this dependency should fit as well. A surrogate that would cover all these chemical and physical properties of the fuel that need to be considered in the engine process, would likely require more components than can be handled in current computational codes. For this reason the surrogate composition needs to be limited.

Usually these surrogates are single component liquids or mixtures of a few simple molecules. A common surrogate is n-heptane, preferred for its comparable cetane number ( 55), according to European and Japanese standards [1]. Additionally, detailed chemical-kinetic mechanisms for low-, intermediate- and high-temperature n-heptane oxidation are available. Others are using n-hexadecane (or cetane, $\left.\mathrm{C}_{16} \mathrm{H}_{34}\right)$ or $\mathrm{n}$-dodecane $\left(\mathrm{C}_{12} \mathrm{H}_{26}\right)$ in order to obtain a high density ratio, similar to diesel engine sprays [2]. Stralin and Wahlin [3] use n-dodecane for its high boiling temperature characteristics, comparable to diesel. 
However, some difficulties exist when selecting a suitable surrogate fuel. For surrogates with comparable cetane number, ignition behavior will not match for a wide range of relevant diesel engine operation conditions [1]. The ignition behavior may also differ since the first stage (low temperature) heat release will exhibit a different dependence on temperature and pressure. One key factor is the multi-component composition of diesel and different oxidation and pyrolysis kinetics. Short molecules are more likely to vaporize first [4] and aromatic hydrocarbons are more likely to delay ignition [5]. Moreover the difference in hydrogen/carbon $(\mathrm{H} / \mathrm{C})$ ratio, molecular structure and local mixture fraction will reflect in different predicted pollution formation. The H/C-ratio can be readily matched with a singlecomponent surrogate, however the similarity of the combustion behavior cannot be guaranteed [1]. Improvements can be made by using a multi-component surrogate. Natelson et al. [6] modeled diesel by using a mixture of (1:1:1) n-decane, n-butylcyclohexane and butylbenzene to approach the average hydrocarbon composition, while Peters et al. [7] proposed a mixture of $70 \mathrm{vol} \%$ of n-decane and 30vol\% methylnaphthalene for the same reason and additionally to improve combustion similarity. The latter mixture is also able to meet comparable cetane number and density. Furthermore, comparable ignition delay and heat release from experiments in an optical engine were found. From experimental investigation one usually concludes that the emission prediction is insufficient. The main reason is that oxidation and pyrolysis kinetics of the combustion are strongly influenced by aromatics, cycloparafins and iso-parafins. This was the main motivation for Gustavsson et al. [8] to add toluene to n-heptane. The local mixing phenomena and local pollutant formation cannot be predicted by single component surrogates as $n$-heptane but the general pollutant formation seemed to be in agreement with experiments.

As a conclusion, while engine experiments with surrogates are capable of providing much insight, they may not accurately reflect the combustion behavior of real diesel fuel; choices only based on physical properties might not be appropriate to predict the chemical processes.

An overview of diesel surrogate can be found in the overview papers of Farrell et al. [1] and Battin-Leclerc [9].

\section{D VAPORIZING SPRAY MODEL}

In direct injected internal combustion engines, such as turbines, piston engines and liquid fueled rocket engines, fuel (and oxidizer) is usually injected as a compressed liquid in a supercritical environment. This has a direct influence on the spray characteristics since in the supercritical state of a fluid, no distinction can be made between liquid and vapor. The concept surface tension, which is a key parameter for breakup, vanishes. The mixing of the spray with the surrounding air cannot be described anymore by breakup and dispersion of droplets; the number of droplets from the spray diminishes and the air entrainment becomes a pure diffusion mechanism, thus the gas jet theory is applicable. This is the main idea of the present 1D model for high pressure vaporizing sprays.

Modeling of sprays has already been confirmed to be very difficult. The breakup of the spray which is usually correlated with the spray cone angle is a struggle for the modeler since the process is influenced by the complex chamber turbulence, nozzle cavitation and turbulence, and temperature and pressure gradients. For 0D and 1D models, the breakup physics are usually avoided, and the cone angle is used as a model input or tuning parameter [2,10]. Further, the supercritical state suggests that the breakup is not considered anymore as the main mixing process, rather the entrainment of hot ambient gases.

\section{$\underline{\text { Methodology }}$}


The spray model used here is based on the model proposed by Payri et al. [2,10]. Their model is briefly described in this section. More details can be found in Payri et al. [2,10] and Desantes et al. [11]. The model considers an isothermal stationary spray as a symmetric cone (cfr. Fig.1) with variable radial values for the axial velocity $u_{c l}$, fuel mass fraction $f_{c l}$ and enthalpy $h_{\mathrm{cl}}$. For modern automotive and heavy duty diesel engines (high pressure commonrail injection) the liquid length is found to be almost independent of the injection pressure. Experimental results suggest that the droplet sizes under realistic engine conditions are so small that atomization is no longer a limitation in the evaporation of the spray. The main contribution to evaporation is then the mixing with the hot surrounding air, resulting in the so called "mixing limited hypothesis"; the vapor and liquid fraction are each time in equilibrium (saturated situation). Further, droplets reach a dynamic equilibrium with the air very close to the nozzle and local transfer rates of momentum, mass and energy between liquid droplets and surrounding air are fast in comparison to the rate of development of the flow field as a whole. Both arguments above assume the spray behavior to be similar to the gas jet theory, even under non-vaporizing conditions in which the problem is undoubtedly a two-phase flow.

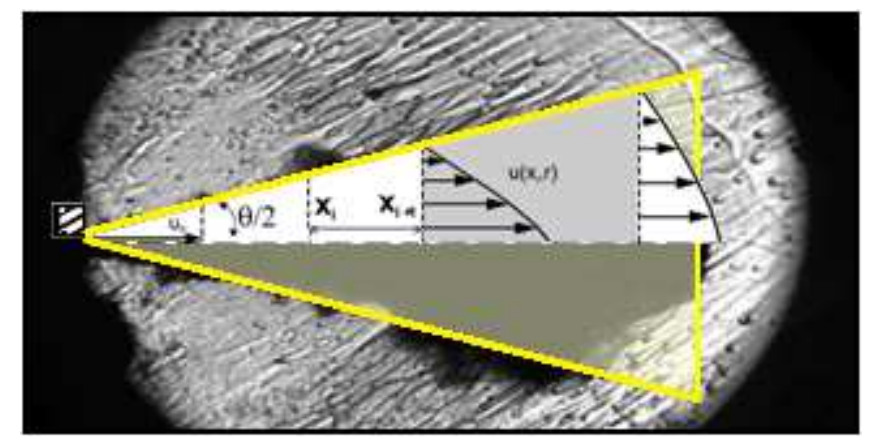

Figure 1: spray development assumed by the 1D model

\section{Hypotheses}

Hypotheses need to be made in order to arrive to a simplification of the complex process of a vaporizing spray. The most important assumptions are listed below and mentioned in Payri et al [2]

- The pressure in the whole spray is equal to the surrounding chamber pressure

- $\quad$ Le, Pr and Sc are set to 1

- the whole spray is considered as a homogeneous mixture with a mixture density $\rho_{\text {mix }}$ (no droplets are considered)

- $\quad$ ambient air is at rest (velocity $=0$ )

- the spray cone angle is constant and input for the model (tuned to experiments)

- Gaussian distributions are used for the conserved parameters axial velocity $\mathrm{u}_{\mathrm{cl}}$, fuel mass fraction $\mathrm{f}_{\mathrm{cl}}$ and enthalpy $\mathrm{h}_{\mathrm{cl}}$. This assumption leads to the following relations:

$$
\frac{u(x, r)}{u_{c l}(x)}=\left[\frac{f(x, r)}{f_{c l}(x)}\right]^{1 / S c}=\left[\frac{h(x, r)-h_{a, \infty}}{h_{c l}(x)-h_{a, \infty}}\right]^{1 / P r}=e^{-k\left(\frac{r}{x}\right)^{2}}
$$

With $k$ the shape factor of the Gaussian profile

\section{$\underline{\text { Derivation and Implementation }}$}

The equations for conservation of fuel mass, momentum and energy are used to describe the vaporizing spray process. This set of equations can be reduced to two equations (Eq.2 en Eq.3); the assumption that leads to Eq.1 implies that the mass and energy equation do not give additional information. 


$$
\begin{gathered}
I_{0}=I(x)=\int_{0}^{R} 2 \pi \rho_{\text {mix }}(x, r) r \cdot u^{2}(x, r) d r \\
\dot{M}_{f, 0}=\dot{M}_{f}(x)=\int_{0}^{R} 2 \pi \rho_{\text {mix }}(x, r) r . f(x, r) \cdot u(x, r) d r
\end{gathered}
$$

All physical properties are only temperature dependent and derived from the DIADEM

DIPPR database and [12].

\section{$\underline{\text { Initial conditions }}$}

The same initial conditions are taken for this work as used in Payri et al. [10] for comparison,

\begin{tabular}{|c|c|c|c|}
\hline$\theta$ & $33.62^{\circ}$ & $\mathrm{u}_{\mathrm{cl}}(0,0)$ & $150 \mathrm{~m} /$ \\
\hline $\mathrm{D}_{0}$ & $200 \mu \mathrm{m}$ & $\mathrm{T}_{\mathrm{f}, 0}$ & $900 \mathrm{~K}$ \\
\hline$x(0)$ & $D_{0} /\left[2 \cdot \tan \left(\frac{\theta}{2}\right)\right]$ & $\mathrm{T}_{\mathrm{a}, 0}$ & $400 \mathrm{~K}$ \\
\hline $\mathrm{f}_{\mathrm{cl}}(0,0)$ & 1 & $\mathrm{P}_{\mathrm{a}}$ & $8 \mathrm{MPa}$ \\
\hline
\end{tabular}
unless stated otherwise (cfr. table 1). Cetane has been used as the diesel surrogate

\section{RESULTS \& DISCUSSION}

This section compares 6 common diesel surrogate fuels: cetane, decane, n-heptane, ndodecane, n-octane and n-heptadecane. The critical temperature and pressure for the investigated surrogates are shown in table 2. These parameters are the only fuel constants (temperature and pressure independent) which can significantly influence the spray formation and combustion. When the spray exceeds the critical conditions, no liquid phase can exists anymore as suggested by the assumption of saturation. First a comparison of the fuel properties used in the 1D model has been done. Next the spray state parameters are considered, followed by the influence of the fuel choice on the modeled results for the liquid length. These results were obtained with the same spray angle input for the different surrogates. As mentioned earlier the spray cone angle was tuned with experiments for cetane [2]. In the last section, the spray angle was tuned for the other surrogates until a similar liquid length was found as for cetane. The results are only based on modeling work and were not confirmed with experiments.

\begin{tabular}{c|cccccc}
\multicolumn{1}{c}{} & cetane & n-dodecane & n-heptane & decane & octane & heptadecane \\
\hline formula & $\mathrm{C}_{16} \mathrm{H}_{34}$ & $\mathrm{C}_{12} \mathrm{H}_{26}$ & $\mathrm{C}_{7} \mathrm{H}_{16}$ & $\mathrm{C}_{10} \mathrm{H}_{22}$ & $\mathrm{C}_{8} \mathrm{H}_{18}$ & $\mathrm{C}_{17} \mathrm{H}_{36}$ \\
$\mathrm{P}_{\mathrm{c}}[\mathrm{bar}]$ & 14.0 & 18.3 & 27.4 & 21.1 & 24.9 & 13.4 \\
$\mathrm{~T}_{\mathrm{c}}[\mathrm{K}]$ & 723.0 & 658.0 & 540.2 & 617.7 & 568.7 & 736.0
\end{tabular}

Table 2: critical properties of the investigated diesel surrogates

\section{$\underline{\text { Fuel parameters }}$}

The model uses only a limited amount of fuel properties. Other fuel properties that might be important for the spray development include surface tension, viscosity and heat conductivity. Viscosity and surface tension will mostly influence the breakup and atomization, together with cavitation and turbulence. This process is avoided by having the spray angle an input for the model. Heat conductivity is considered to be infinitely high by the mixing limited hypothesis (no time is required to heat the fuel by conduction). The saturation pressure $\mathrm{P}_{\text {sat }}$ is considered and will determine the vapor fraction $\mathrm{Y}_{\mathrm{fv}}$. The heat capacity $\mathrm{c}_{\mathrm{p}}$ will influence temperature by the heat that can be absorbed by the fuel. The mass flow rate and momentum will be strongly depending on the density of the spray $\rho_{\text {mix }}$, determining the axial spray velocity. The 6 different surrogates show significant differences for liquid density, saturation 
pressure and enthalpy as shown in Fig. 2 for a temperature range from $350 \mathrm{~K}$ to $1350 \mathrm{~K}$. For low temperatures the density difference is small, but becomes bigger when reaching the critical temperature. The main difference between the investigate alkanes is the chain length; the more the length approaches cetane, the more the results are in agreement with cetane. The liquid density has an important contribution to the total spray density since the value is about 10-40 times higher than the vapor density. The big difference compared to the reference surrogate cetane can be reduced if the spray density is considered: near the critical temperature $T_{c}$, the liquid fraction will be small (cfr. section State parameters). The saturation pressure for the different surrogates shows big differences. In the vaporizing spray the influence of the saturation pressure is found in the assumption that the spray is saturated on every time and position:

$$
\varphi(x, t)=\frac{1-f(x, t)}{f(x, t)} \frac{M_{f}}{M_{a}} \frac{P_{s a t}-1}{P_{a}}
$$

\section{$\underline{\text { State parameters }}$}

State parameters are independent of the spray process in the model and determined by the fuel mass fraction $f_{c l}$, but might have an important influence on the spray modeling results. For the vaporizing spray these include the spray density, temperature, vapor fraction and saturation pressure. A relative comparison with cetane is done for the liquid density and saturation pressure to better point out the difference (cfr Fig.3). The vertical dotted lines represent the fuel fraction at which the liquid fraction becomes zero $\left(Y_{v}=f=f_{\text {evap }}\right)$, also defined as the spray liquid length. The amount of fuel vapor under saturated conditions is completely determined by the saturation pressure as mentioned in the previous section. As a consequence, the big differences in saturation pressure do influence the fuel vapor \& liquid fraction. The fuel fraction $\mathrm{f}_{\text {evap }}$ differs from 0.25 up to 0.46 for the investigated surrogates. As could be expected, the highest $f_{\text {evap }}$ corresponds with the most volatile surrogate (= surrogate with the highest saturation pressure). The differences among the investigated fuels for the temperature dependence of the density was rather small and has also little effect on the density-fuel fraction relation as was found on Fig.4a \& c. The differences are biggest for high fuel fractions since these conditions represent the biggest amount of (liquid) fuel.
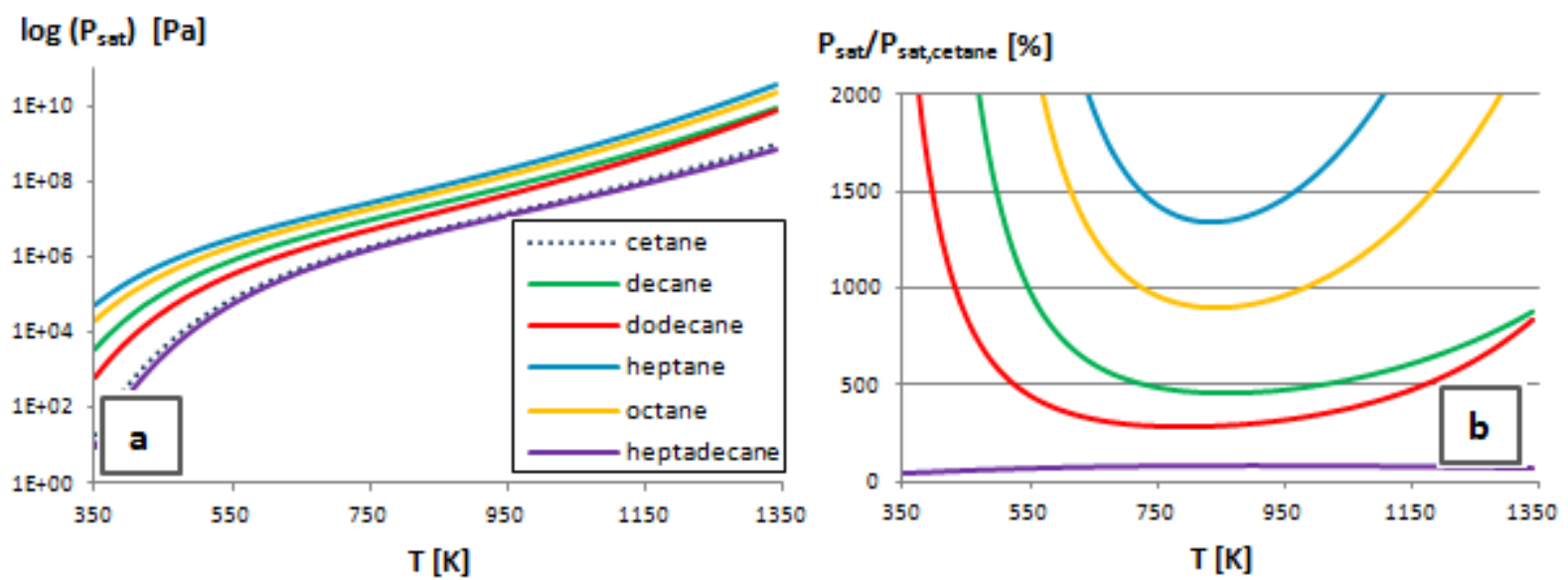

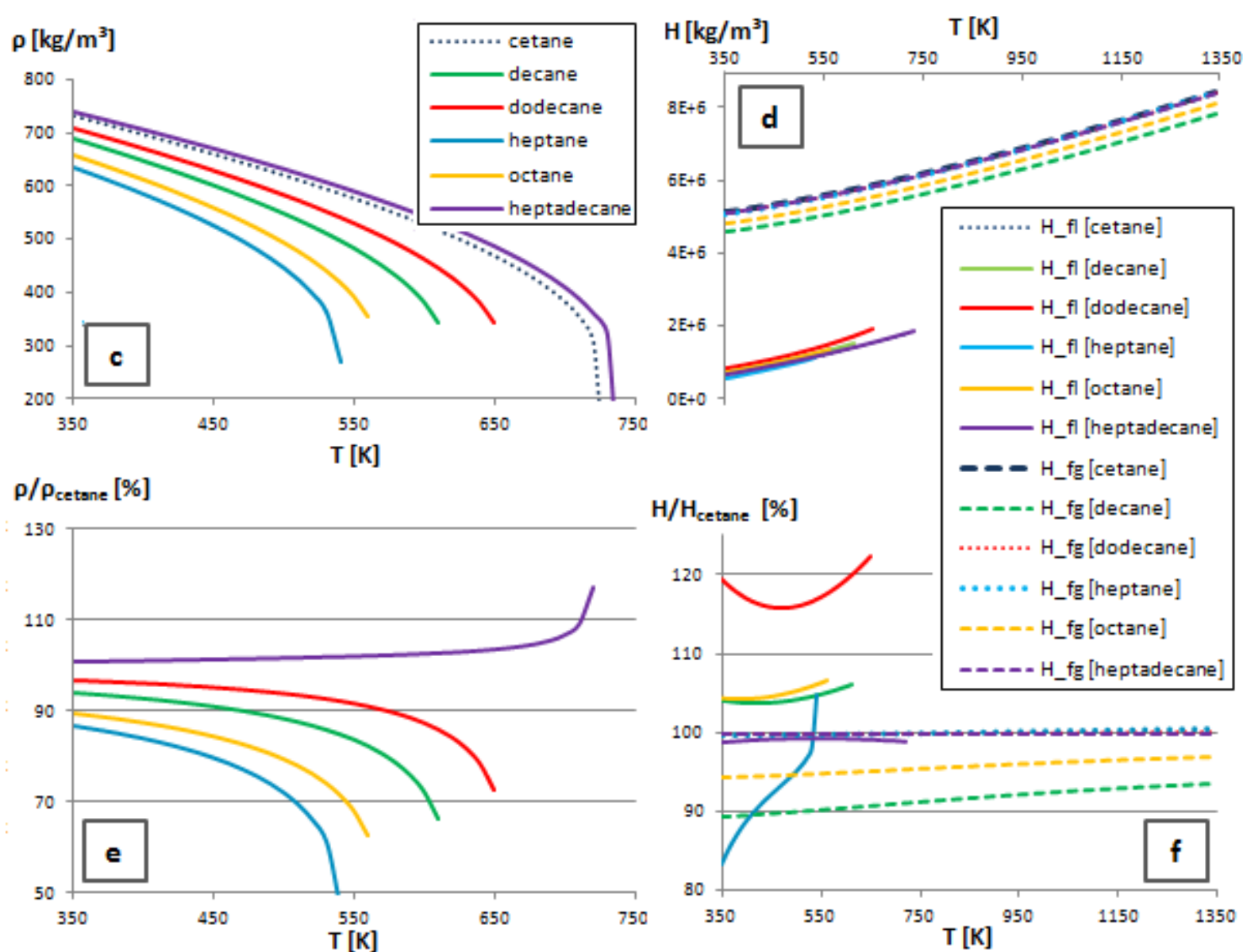

$\rho / \rho_{\text {cetane }}[\%]$

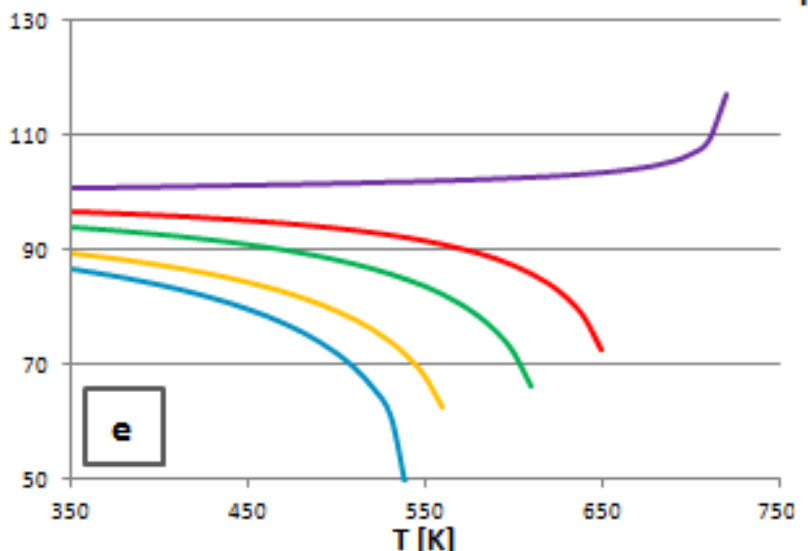

Figure 2: (top left) liquid density for 6 diesel surrogates, (bottom left) liquid density relative to cetane, (top right) saturation pressure for 6 diesel surrogates, (bottom right) saturation pressure relative to cetane

\section{$1 \mathrm{D}$ vaporizing spray model}

The axial spray velocity $u_{\mathrm{cl}}$ along the spray axis is plotted in Fig. 4 for the different surrogate fuels. Again, the significant differences in the state parameters are reflected in the position of the liquid length. A summary for the different surrogates of the liquid length (xevap), temperature (Tevap) and fuel fraction (fevap) at total evaporation is given in Fig.5. These spray properties are crucial for the model since start of combustion is determined by the combination of mixture energy (dominated by the temperature) and local mixture fraction, apart from the fuel composition. Further, if the liquid fuel reaches the wall of the cylinder, incomplete combustion may occur, resulting in soot and UHC emissions. From these results, the cylinder needs to be more than twice bigger before the cetane fuel is totally evaporated compared to heptane.
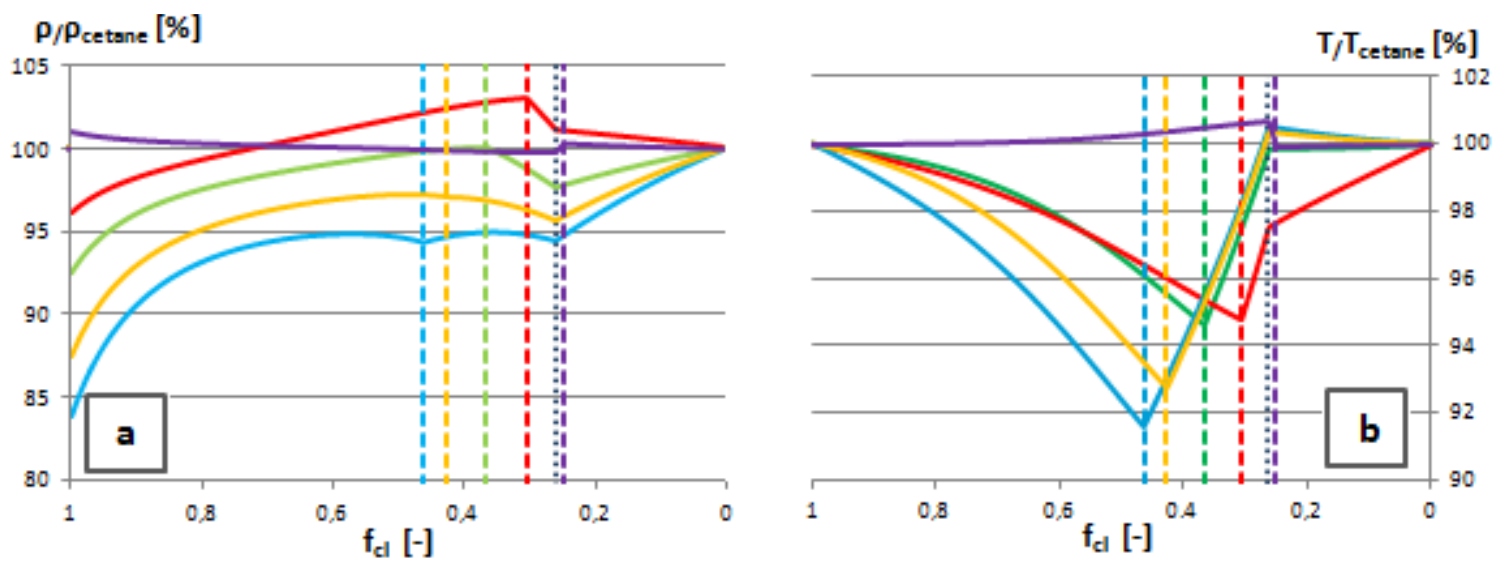


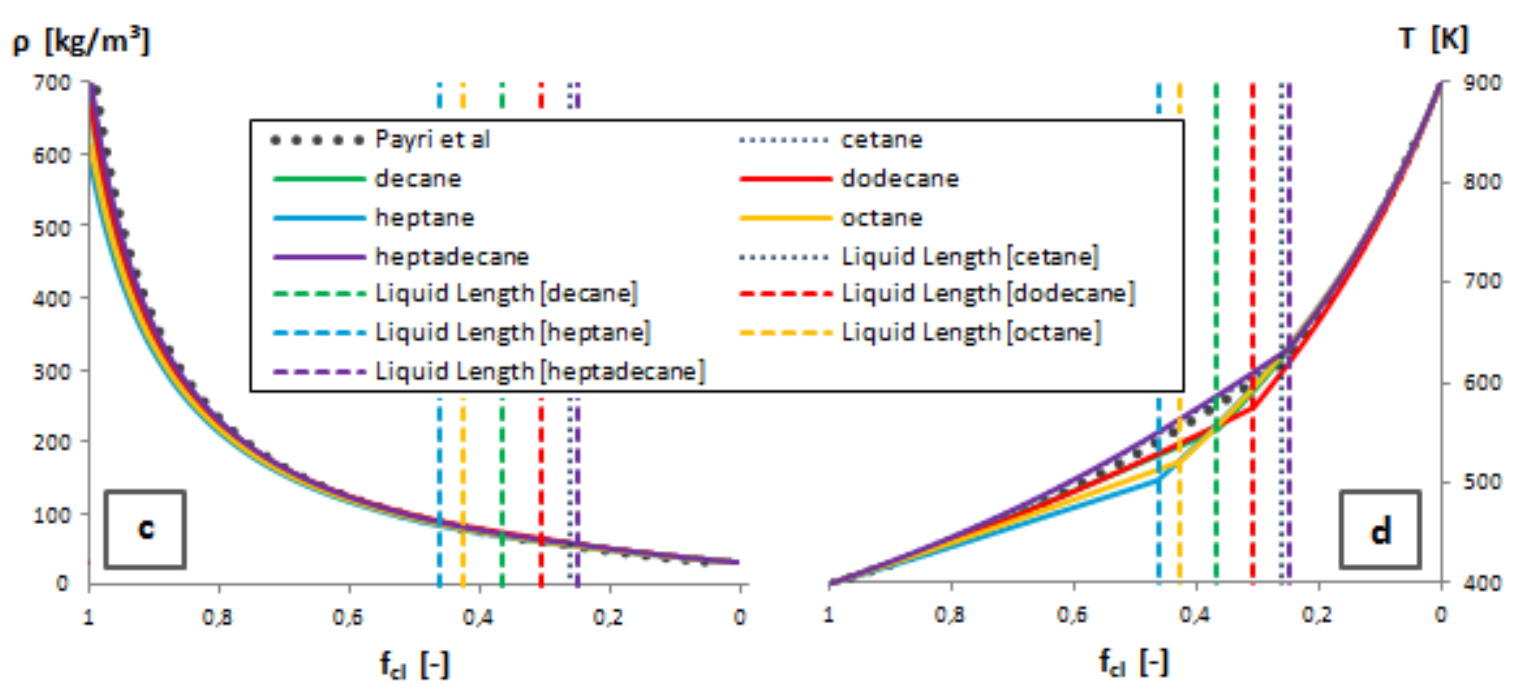

Figure 3: comparison of the relation state parameters among the fuels

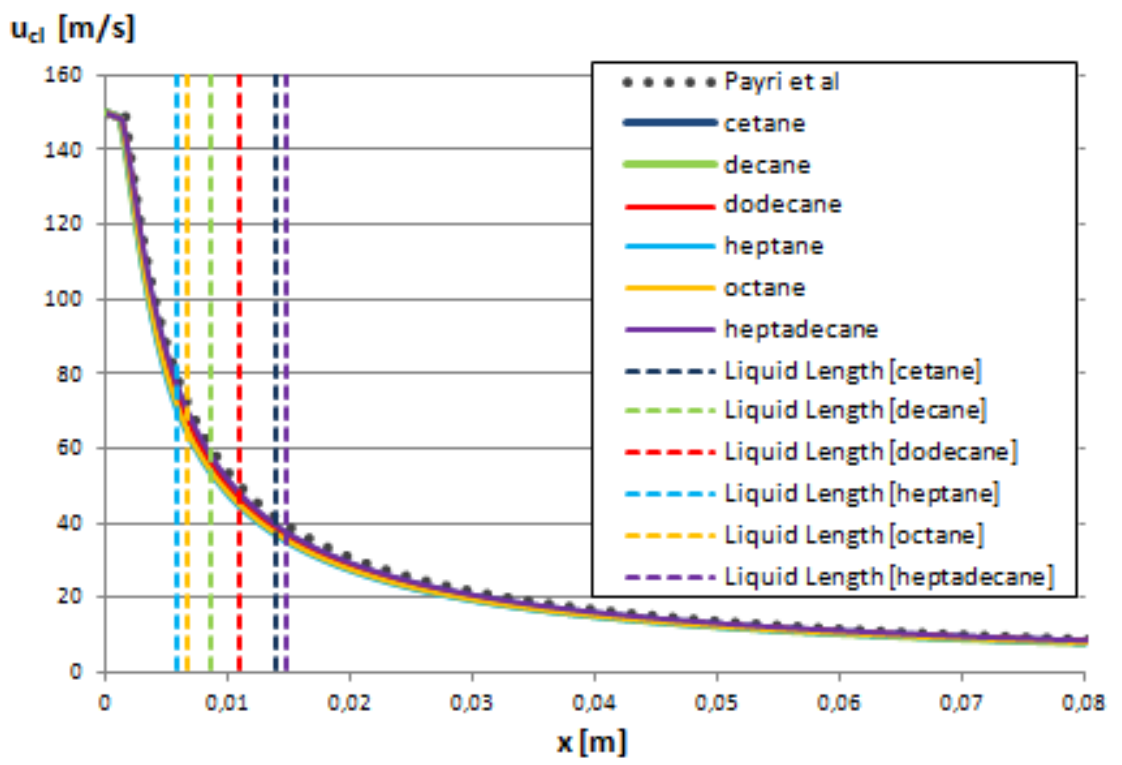

Figure 4: summary of the comparison of the liquid length (xevap), temperature (Tevap) and fuel fraction (fevap) at total evaporation between the different surrogates for the same boundary conditions (the y-axis shows the percentage compared to cetane, the values on the boxes represent the absolute value)

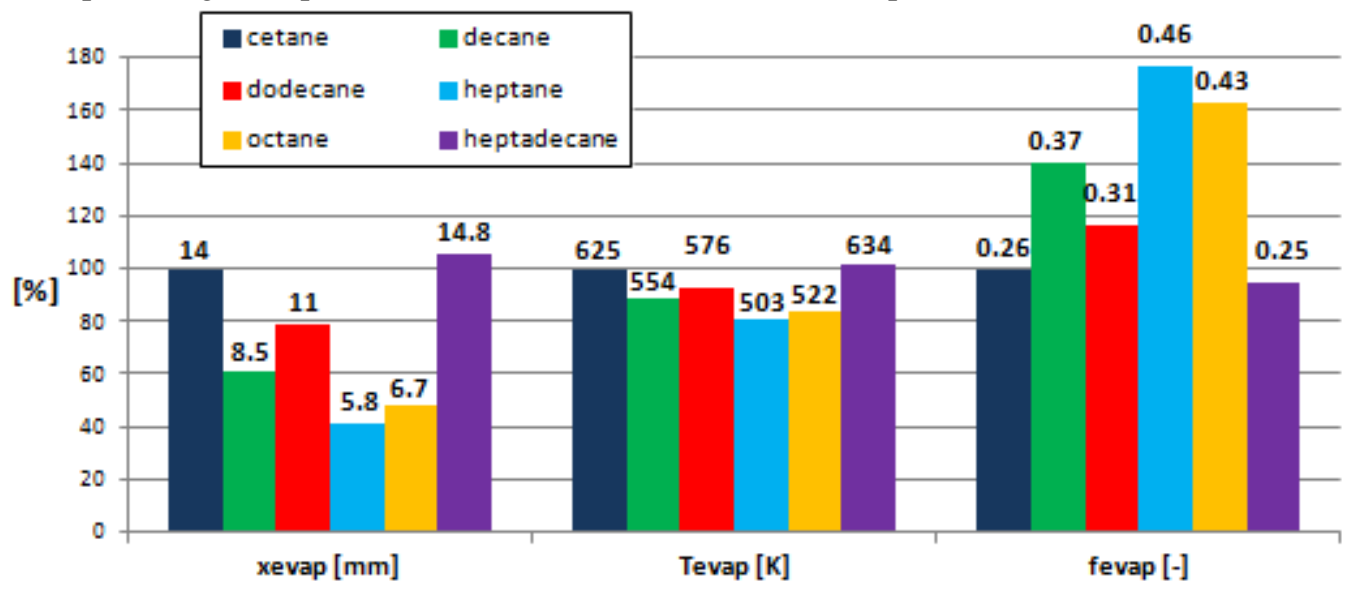

Figure 5: summary of the comparison of the liquid length (xevap), temperature (Tevap) and fuel fraction (fevap) at total evaporation between the different surrogates for the same boundary conditions (the y-axis shows the percentage compared to cetane, the values on the boxes represent the absolute value) 
The fuel properties were the only changes made to the spray model. All other parameters and initial conditions were kept the same, including the spray angle which was tuned for cetane by Payri et al [2] and not for the other surrogates. In this section, the spray angle was tuned for each surrogate in such way that the obtained liquid length is the same as for the reference surrogate, cetane. From experimental efforts it is known that the determination of the spray angle is very difficult (standard deviations between 5 up to $10 \%$ ) and strongly depends on the used definition [13]. This is the main motivation to choose the spray parameter as a tuning parameter. Nevertheless, the difference in spray angle is up to more than 50\% compared to the reference surrogate (cfr Fig 6). Due to the hypotheses, this has significant consequences for the local mixture fraction and axial velocity, which deviates a lot from the cetane values and might affect the ignition, combustion progress and pollutant formation. This was not yet investigated in this work.

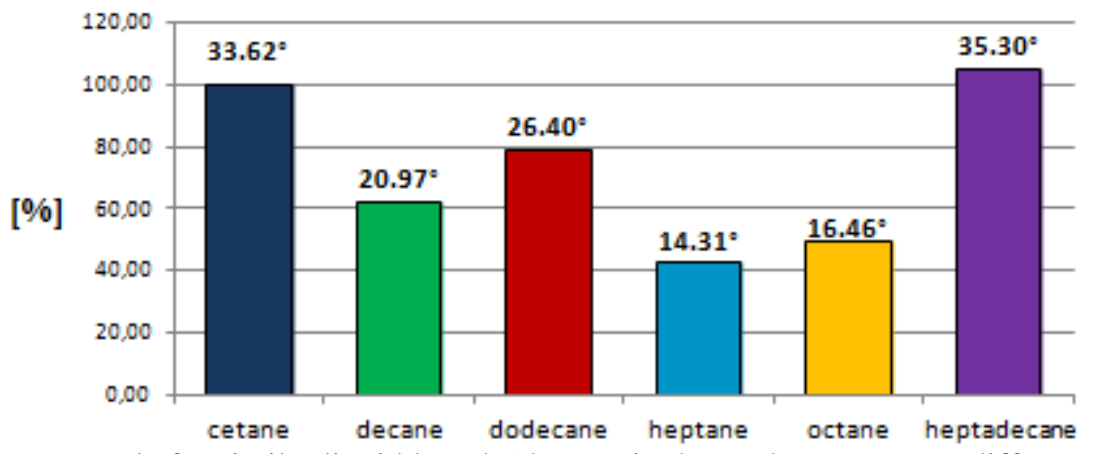

Figure 6: tuned spray angle for similar liquid length (the y-axis shows the percentage difference compared to cetane, the values on the boxes represent the absolute tuned spray angle)

\section{CONCLUSIONS}

Surrogates are capable to provide insights in the atomization and combustion process under high temperature and pressure conditions, but care should be taken when using surrogates to predict the diesel engine outputs. Only vaporizing sprays were investigated by the use of a simplified spray model. The model is able to predict experiments with cetane as was demonstrated by Payri et al. [2]. The quantitative results may not be directly useful for further calculations, since all calculations were based on experiments with cetane. Nevertheless some important remarks can be made concerning the use of surrogates in modeling work. The following conclusions can be derived from this work:

- A real single- or few-component surrogate that would cover all the chemical and physical properties of diesel relevant for in-cylinder processes is not possible, both because of the available information as for the required resolving time

- For simplified 1D models, the fuel parameters with the strongest influence on the hypotheses should be considered when choosing a surrogate. In the considered model, the mixing limited hypothesis states that vaporization is determined by the saturation pressure. Strong differences in this parameter among the surrogates will result in strong differences of the spray characteristics.

- Axial spray velocity and local mixture fraction are difficult to measure experimentally and are usually derived from modeling work. Parameters in the model are tuned in such way that the more readily measurable parameters fit to the experiments. For this model, the spray angle is tuned. Depending on the surrogate significant different local 
mixture fractions (f) and velocities are found. This will definitely influence the succeeding ignition, combustion and emission formation.

\section{ACKNOWLEDGEMENTS}

The research is carried out in the framework of a Ph.D. which is funded by a grant (SB81139) of the Institute for the Promotion of Innovation through Science and Technology in Flanders (IWT-Vlaanderen). This financial support is gratefully acknowledged.

\section{REFERENCES}

[1] Farrell J.T., Cernansky N.P., Dryer F.L., Friend D.G., Hergart C.A., Law C.K., McDavid R.M., Mueller C.J., Patel A.K., Pitsch H., "Development of an experimental database and kinetic models for surrogate diesel fuels" [J]. SAE2007-01-0201

[2] Pastor J.V., Lopez J.L., Garcia J.M., Pastor J.M., "A 1D model for the description of mixing-controlled inert diesel sprays" [J]. Fuel ,87(2008);2871-2885

[3] Stralin P., Wahlin F., Angstrom H.-E., "Effecs of injection timing on the conditions at top dead center for direct injected HCCI" [J]. SAE2003-01-3219

[4] Struckmeier D., Tsuru D., Kawauchi S., Tajima H., "Multi-Component Modeling of Evaporation, Ignition and Combustion Processes of Heavy Residual Fuel Oil" [J], SAE paper 2009-01-2677

[5] Wanga H., Warner S.J., Oehlschlaeger M.A., Bounaceur R., Biet J., Glaude P.-A., BattinLeclerc F., "An experimental and kinetic modeling study of the autoignition of a-

methylnaphthalene/air and a-methylnaphthalene/n-decane/air mixtures at elevated pressures" [J], Combustion and Flame 157(2010);1976-1988

[6] Natelson R.H., Kurman M.S., Cernansky N.P., Miller D.L., "Experimental investigation of surrogates for jet and diesel fuels" [J]. Fuel 87(2008);2339-2342

[7] Peters N., Pitsch H., Barths H., "3D simulation of DI diesel combustion and pollutant formation using a two-component reference fuel" [J]. Oil \& Gas science and technology, 54(1999)2;233-244

[8] Gustavsson J., Golovitchev V.I., "Spray combustion simulation based on detailed chemistry approach for diesel fuel surrogate model" [J]. SAE2003-01-1848

[9] Battin-Leclerc F.,'Detailed chemical kinetic models for the low-temperature combustion of hydrocarbons with application to gasoline and diesel fuel surrogates" [J]. Progress in Energy and Combustion Science 34 (2008) 440-498

[10] Payri R., Desantes J.M., Garcia J.M., Salvador F.J., "A contribution to the understanding of isothermal diesel spray dynamics" [J]. Fuel 86(2007)1093-1101

[11] Desantes J.M., Salvador F.J., Lopez J.J., De la Morena J., "Study of mass and momentum transfer in diesel sprays based on X-ray mass distribution measurements and on a theoretical derivation" [J]. Exp. Fluids 50(2011)233-246

[12] Perry R., Green D.W., "Perry's chemical engineers' handbook” [M]. ISBN-10:

0071422943

[13] Galle J, Demuynck J, Vancoillie J, Verhelst S, "Spray parameter comparison between diesel and vegetable oils for non-evaporating conditions" [J]. SAE paper 2012-01-0461 